\title{
Becoming Horse in the Duration of the Moment: The Trainer's Challenge
}

Stephen J. Smith, Simon Fraser University, Burnaby, BC, Canada

Email: Stephen_smith@sfu.ca

\section{Abstract}

Language skirts the somatic fringes of the moment, particularly in practices where the powers of human speech and writing seem nullified. Horse training is one such practice. We tell stories of horse training that sensitize us and bring us close to creatures whose movements, resonating with our own, connect us to a prelinguistic, animate world. In so doing, we bridge the gap between the reflective detachment of our customary, wordy practices and the wordlessness of pre-reflective animality. Yet a phenomenological discursiveness shows us how vital moments of "becoming animal" can be consciously and linguistically sustained. "Becoming horse in the duration of the moment" addresses the corporeally-charged consciousness of being with horses on the ground and in the saddle. This paper describes a relationality and temporality that, though mostly wordless in strictly human terms, speaks a sophisticated language of moment resonance. In so doing, it contests the dualisms of verbal and non-verbal discourses, the separation of humans and other animals, and the divisions that keep somaticity on the fringes of consciousness. It responds to the ecological challenge to get beyond the linguistic appropriation of the other, human speciesism and anthropomorphic projections, in order to discern the kinesthetic and energetic expressivities of connecting with other beings and with the elements of animate existence. Horse training provides a case for "living" in the somatic fullness of the moment.

\section{Introduction}

The "linguistic turn" in the human sciences has been upon us for some time. Since Wittgenstein drew attention to "language games" and de Saussure argued the inseparability of words and meaning, it has become impossible to ignore the constitutive role language plays in structuring our lived realities. What we experience is inseparable from the linguistic framing of experience such that what is seen, felt, tasted, touched, heard and smelled is already loaded with sense-making structure. More recently, though, the "corporeal turn" has complemented yet also challenged the "linguistic turn." Maxine Sheets-Johnstone (2009) signaled it some twenty years ago with the increasing attention 


\section{Smith}

given to embodiment and to the ways in which the body has been overlooked as generative and expressive of the multiple and diverse ways of being in the world. Theorists from Maurice Merleau-Ponty to Judith Butler, Michel Foucault, Jacques Derrida, Julia Kristeva, Luce Irigaray, and Michel Seres have shown how bodies are inscribed, performed and co-extensive with all meaning-making. Bodies are sites for, and the physiognomic and phenomenal affordances of, human consciousness and its reaches. Thus, if it is language all the way down, then surely it is the body and its performativity all the way up.

What appears missing in both the linguistic and corporeal turns is a concern for matters that extend beyond the human realms. To be sure, there is major interest in the human "other," and indeed an "otherness" that is technologically mediated, but the other that is "more-than-human” (Abram, 1997, 2010) has been largely absent. That is, until now. We are beginning to see what may now be called the animal turn across the human and social sciences and what this means, not just in terms of a ready grasp on environmental ethics, but more particularly as an address of "the question of the animal that therefore I am" (Derrida, 2008). This animal turn is about more than "companion species" (Haraway, 2008) and the care of the animals in our daily lives, whether they be our pets (Fudge, 2008) or the animals in the human food chain (Bekoff, 2010). "The question of the animal from Heidegger to Derrida" (Calarco, 2008; Atterton and Calarco, 2004) brings together "animal ethics and philosophy of the body" (Acampora, 2006) and touches down in pedagogical concerns about "why the wild things are” (Melson, 2001) and how it is possible that animals can figure large in the lives of children and adults.

The animal turn foregrounds "nature" and "animality" in ways that Merleau-Ponty indicated in his last writings (Merleau-Ponty, 2003). "Nature" is not so much the background against which human nature, at least for a perceiving, sensing being, is wrested and brought to a separate and higher level of consciousness. Rather, there is the "intertwining" of humanity and animality in "the flesh of the world" wherein "the relation of the human and animal is not a hierarchical relation, but lateral, an overcoming that does not abolish kinship" (p. 268). This "laterality" becomes recognizable in our kinship with animals and through the radical reflection on this kinship that forges "a new path for phenomenology, one that breaks with its tradition of human exceptionalism" (Toadvine, 2009, p. 94). The "animal turn" is the occasion to reconsider the linguistic appropriation of the other, and to contest anthropomorphic projections of human embodiment, not in outright dismissal, but through a phenomenology of the "paradoxical conjunction of transcendence and immanence" that is "our experience of the world" (p. 132). Where the linguistic turn has indicated the human species' transcendence of nature, and where the corporeal turn has indicated the human species' immanence in nature, or at least human nature, the animal turn is the phenomenological reminder of the ontological grounds, i.e. animality, for the seeming transcendence of a nature that is always immanently natural. This turn in phenomenology, within the larger turn in the human and social sciences, aims essentially at a "rejuvenated relationship with nature" (pp 134, 135) that is the ontological condition for thinking through our various aesthetic and ethical relations with other beings. 
Such a phenomenology pays heed to the "visible and invisible" actions, touches, senses and energetic transfers of interspecies connectivity. It is concerned with contact that extends from postural, positional and gestural mimicry to expressive and creative resonance with other beings and with the elements of animate existence. It is attentive especially to "intersomaticity" as the "overlay" and "intertwining” of different species" "bodily modes of address to the world...in which felt senses of bodiment are shared and potentially in dynamic relation” (Acampora, 2006, p. 18). Such a phenomenology is now taken up through examples pertaining to the training of horses. In the following sections of this paper I address the deepening moments of engagement and felt connectivity in this training process. The first section provides some discussion of current discourses of horse training that turn on the different stories we choose to tell ourselves about horses and humans and how they relate to one another. The second section gives evidence for and examples of the significance of the trope "becoming horse" as not only a way of speaking of horses, but also a way of experiencing an intersomatic connection to horses. And the third section situates this analysis within a broader discussion of "animate consciousness." We will see how "becoming horse in the duration of the moment" is especially telling of our linguistically transcendent, bodily immanent and animatedly conscious relations with horses and with the world we share with them and other life forms. We will also assess the possibilities of "becoming horse in the duration of the moment" through specific reference to the work of trainers who, unlike many philosophers, live and work daily with animals.*

\section{Training Horses}

The notion of "breaking" horses has given way to "horse gentling," "colt starting," "backing the horse" and "joining-up." A "revolution in horsemanship” was signaled in North America in the use of training methods that broke with the sheer exercise of force and suppression (Miller and Lamb, 2005). Known mostly to a wider public through Nicholas Evan's best-selling book “The horse whisperer” (Evans, 1995) and through the popular movie of the same name, this approach to horse training advocates understanding horses on their own terms and engaging with them in terms of herd dynamics, using body language that approximates to horses' ways of communicating with one another. Instead of restraining them through tie-downs, hobbles and harsh bits, horses are worked from the ground up, at liberty, or longed within the boundaries of round pens, as their trainers develop a feel for their movements, and follow that feel from ground work to riding horses under saddle. Popularized by horsepeople such as Ray Hunt, Tom and Bill Dorrance, Leslie Drummond, Monty Roberts, Buck Brannaman, Pat and Linda Parelli, Cinton Anderson, Jonathan Field, Mark Rashid, Chris Irwin, Stacy Westfall and GaWaNi Pony Boy, "natural horsemanship" has set a new, enlightened standard in horse training.

This approach to treating horses more kindly is not new. The Renaissance in Europe was also a time of enlightened horsemanship, with the development of equestrian arts founded on similar treatment of horses and with deferral to the original ideas of Xenophon on "the art of horsemanship" (Morgan, 1962). One might also refer to other cultural traditions of horsemanship, from the Plains Indians, the Charros and Vaqueros of Mexico and South America, to the secret societies of horseman in Great Britain. A fuller 
tracing of the advent of "natural horsemanship" is not, however, central to the purposes of this paper other than as an indication of certain long-standing precepts of horse training that have to do with care, respect, admiration and valuation of horses and their innate abilities. Also, "natural horsemanship," while laying a broad foundation of groundwork, is ultimately concerned with getting into the saddle. Horse riding, from pleasure hacking to the equestrian artistry of the high school menáge, is its teleology. While not ignoring horse riding as the goal of much horse training, there is a broader field of work that includes the use of trained horses in therapy, albeit mostly as therapeutic riding horses, as service animals, companion species, "guides” in experiential education, as well as performers in circuses, horse operas, and equestrian shows. Horse trainers such as Klaus Hempfling and Alexander Nevzorov, Magali Delgado and Frédéric Pignon, and the Knie circus family have expanded the paradigm of horse riding to show what is possible when horses are treated as partners and "interlocutors" in an ongoing conversation on the very nature of the human-horse relationship.

This relational practice not only eschews forceful dominance and the subjection of the horse by restraint, pressure and coercion into fearful compliance, it also advocates an appreciation of the horse as a sentient being whose interests and inclinations need to be respected. The horse is attributed not only a certain intelligence, but also an emotional life that needs to be respected (Bekoff, 2007). David Walser, writing about Delgado's and Pignon’s training approach to their Lusitano stallion, Templado, states:

What happened was not so much that they had to find new ways of treating this horse. It was more a change of attitude and a fundamental one - in effect, a change of direction. Instead of saying to themselves, as they had done so far, "How can I get this horse to do want I want, albeit in the kindest possible way?" they learned to ask, "What would this horse like to do?” Then slowly but surely they built on what the horse told them. Instead of thinking of themselves as teachers, they had to become pupils. They felt they were entering new territory, one that could only be explored by an absolute determination to put the horse on a more equal footing with themselves and to abide by an immutable set of principles, based on respect and love. (Pignon, Delgado and Walser, 2009, pp. 17, 18)

There is something deceptive in these words and in the tendency to interpret caring for horses as denying all control and all domination. Seemingly the opposite is stated by Klaus Hempfling:

It is absolutely essential for his psychic wellbeing that we dominate him completely! Only then can he concern himself with all the secondary questions of life, arrive at a peaceful state of mind, and find his stability and equilibrium. (Hempfling, 2001, p. 29)

Without dominance, achieved through the nuances of bodily communication, there is, according to Hempfling, no proper basis for the establishment of trust between human and horse, without which nothing meaningful occurs. Control and domination need not be 
oppressive, subjugative, or coercive. These trainers are, instead, pointing to a relationship that needs to be established, not strictly on human terms, but in terms of the hierarchical dynamics that horses understand.

We seem to be caught between different stories of relating to horses, different stories we tell ourselves and have received from others, and stories that turn us linguistically to possible relationships with horses. The stories of Pignon's and Delgado's training successes, as with Hempfling's stories of working with wild Andalusian stallions, feed our imaginations of being with our own horses in harmonious, playful, trusting and respectful ways; yet they are different stories, and not just in the details. Animal trainer and philosopher, Vicki Hearne, suggests that the stories we tell ourselves about animals and our relations with them are self and other confirmatory. The words we use, the metaphors, the tropes, enable us "to dissolve problems instead of solving them" so that we can get on with the business of working with animals (Hearne, 2007, p. 27). Consider, again, the issue of dominance.

Vicki Hearne, like Klaus Hempfling and other horse trainers, lauds dominance as essential to the safety of the trainer and the well-being of the horse. But she is careful to distinguish coercion from the methods used to train a fully responsive horse:

Disciplinary relations of command and obedience are precisely a means to create and maintain stable and civil relations between different kinds of beings, not only among individuals of the same species, but also between representatives of different species. Trainers such as Hearn and Roberts argue that in training dogs and horses we create forms of society that establish domestic animals not only as our interlocutors in certain contexts, but as moral beings capable of being endowed with certain rights and duties. (Patton, 2003, p. 95)

Horse training is not a matter of showing the horse who is boss but, rather, of creating a relation of total trust and confidence between human and horse within "the myriad moments of transformation that are daily fare in the good trainer's world" (Hearne, 2007, p. 122). Hearne is dismissive of "writers who know nothing to speak of about horses" who harp on the oppressive rendition of submission and conveniently overlook the stories of horse training as "a trope of courage and genuine discipline” (p. 123). The broad brushstrokes of horse training create submission of the horse to the trainer's requests, but this submission is but a portal to a far more nuanced relationship about which many stories of courage, valor, beauty, redemption and so on might be told. In other words, horse trainers, along with writers of popular horse stories, tell quite different tales than those told in the academy about power, coercion and the subjugation of another's will.

There are, of course, good stories of horses and good training stories. These are, generally speaking, kinder stories, gentler stories, enabling stories as opposed to stories of cruelty, mistreatment and sheer subjugation of horses to human purposes of, say, war, commerce, or even recreations such as horse racing, rodeo and competitive dressage. What defines a good story is, beyond its compelling plot and vivid characterizations, the 
fact that it touches on some sense or senses of truthfulness. Take, for example, the almost universal trainer's story of "herd dynamics" and the methods of "pressure and release." According to this story, horses observed in the wild have a pecking order, with dominance established by the lead mare. The horse trainer's challenge is to approximate these herd dynamics in a human-horse partnership wherein dominance by the human and the continual testing of that dominance by the horse is essential to the dynamics of progressive training. The primary method of dominance, whereby the human creates a pressure aid or cue from which the horse must move away in order to gain release, is justified as similar to the means whereby the mare controls the herd and the herd members establish their respective places. This story rings true, even in the face of a human handler who little resembles a lead mare, until a truer story is told.

"Clicker training” is such a new story in the horse training world, although certainly the method is nothing new to dolphin trainers, dog trainers and to those versed in the science of "operant conditioning” (see Foley, 2007; Karrasch, Karrasch and Newman, 2000; Kurland, 2007; Grandin and Johnson, 2009, pp. 128-135). The appeal of clicker training as a form of "operant conditioning" is its reliance on positive rather than negative reinforcement such that one seeks the desired behavior through reward shaping rather than demanding it through pressure and aversion release. It is appealing as a means of creating a kinder, gentler, more responsive and "beautiful relationship" between human and horse (Grandin and Johnson, 2009, p. 135). And in this greater regard for the feelings, emotions, sensitivities and intelligence of the horse, this method of training seems more truthful. But even clicker training and, indeed, other positively reinforcing methods of shaping horse behavior, cannot escape the critique of subjugating the horse's natural inclinations to the actions the trainer wants the horse to perform. "Endo-tapping," which is a percussively-applied method of stimulating the release of endorphins, produces evident relaxation, freeing of joint movement, desirable raising of the horse's back through various gaits, and subsequent collection in a "natural frame" (see Dufresne, 2011; Giacomini, 2010). But still it is a method applied to the horse in keeping with human intentions of improving the horse's functionality. As Patton (2003) and others have pointed out: Would a horse left free to its own devices perform dressage movements in test sequence? Would a horse clear fences, and consecutive ones at that, if left in a paddock with jumps laid out? What truth is there in the belief of classical horse training that it is right to bring as close to perfection as possible the gaits that are natural to the horse, the performance of which is expressive of the horse's own highest purposes? Here we need venture into a realm of horse training that refuses any force or coercion, exposing any abuse to public condemnation and, instead, seek to work sympathetically, energetically and synchronously with horses.

Alexander Nevzorov speaks less behavioristically and more quantumly about the human-horse dynamic. He attends specifically to a relationality that, mostly wordless in strictly human terms, suggests an elemental, energetic language of postural, positional, gestural and expressive connection. Without bridle, bit or saddle, he works expressively, playfully with his horses to create the movements of "haute ecole." This schooling, or "understanding" as Nevzorov prefers to call it, is premised on tapping into the naturalness of the horse's movements and working with what the horse offers the trainer rather than 
what is demanded by the trainer of the horse. Nevzorov's methods draw upon understandings of horse anatomy, physiology and behavior to achieve, through liberty work, a level of collection and gait development that is otherwise achieved in high school training and modern dressage (Nevzorov, 2006; May, 2008). Although distinctively focused on the classical goals of horsemanship, the sympathetic, energetic sense of human-horse connection underlying Nevzorov's methods is shared by many contemporary horse trainers.

Brendon Carpenter (2006), for example, advocates "energetic training” that is focused on the emotional states of the human and the horse. The key part of this practice is becoming attuned to one's energy state so that, deliberately and with very clear intent to the horse, one can use that energy state to motivate and direct the horse's movements. Carpenter writes:

When I am working with a horse that is excitable and nervous, I think "low energy" and re-create the feeling my body has felt before, like it does when I'm tired. My energy will drop in my body and not radiate away from me. The energy flow slows and becomes closer to me. The horse feels this lowering of the energy and is influenced by the lower energy emotion I am projecting. The horse will reflect what I do because reflection is what it does naturally in the herd. The individuals of the herd reflect the emotion and behaviors of the other herd members. By contrast, if I have a horse that is lazy or dull, I will bring my energy up using the same thought techniques. I think "high energy" and recreate the feeling my body has felt when I am happy, or excited. My energy comes up in my body and radiates away from me in all directions. The energy flows faster and with more energetic movements within and around me. This too influences the horse to reflect what I bring to the relationship and helps to increase its behavior to be more energetic. (p.2)

Visualizing energy connections and transfers is a result of the trainer managing his or her emotions and directing their force, as necessary, through postural, positional, gestural and expressive signaling of behavioral intent to the horse. Sometimes this energy direction serves to "bring up life" in the horse; other times, it is a means of pacifying the horse, "reining in" the energy for movements that require enhanced and measured concentration.

The clarity and control of one's body language are evidently the defining features of the trainer's effectiveness. The more he or she is conscious of, and in control of, the specific kinetic ways of tapping into the horse's body language, the more effective he or she is as a trainer. Human and horse become connected "within a larger, somatic framework of interspecies communication” (Patton, 2003, p. 89). Yet, it is precisely here, in this connectivity, that the one-sidedness of the communication breaks down. Just as the human directs the horse through a display of intention, it is also the case that the horse's movements become a prompt for the trainer's movements. The latter may well "shoulder the burden of knowing” (Hearne, 2007, p. 163) what the horse wants and what is wanted 
of the horse, but only if the trainer takes up for himself or herself the "knowledgeable" story of the horse's development. But what if we put less emphasis on knowledge, as in knowing about horses and how we can control and manage them, and more emphasis simply on being with horses such that a more dynamic, in the moment, partnership might be possible? Body language awareness then provides a means of connecting with horses with visible affect and effect, with heightened tactility and kinesthetic registers of being with animals that are not as controllable and manageable as are our own visible actions the postures, positions, gestures and expressions - of signaling body language. Can we even take on the body language of a species that seems more kinetically and kinesthetically adept than we are? Can we be receptive somatically to what the horse can show us energetically through a range of specific motions?

"Entrainment" is increasingly acknowledged as a distinctive feature of being connected with other beings. This is the process whereby two systems of certain oscillating functions fall into synchronous patterns, say, of breathing, or with respect to their heart rates. Entrainment occurs invisibly, mostly pre-consciously, as energy becomes balanced between the two beings. This is also called "coherence." With horses, entrainment or coherence can become the basis of our relation to them when we put aside the self-awareness of trying to direct the horse, or otherwise controlling its movements, and put ourselves into the energetic spaces of prompting and responding to the horse's motions. We engage in a connection of "symphysis," not empathy, or sympathy, but a connection of felt, energetic resonance:

Symphysis...is meant to convey the sense of sharing with somebody else a somaesthetic nexus experienced through a direct or systemic (inter)relationship. In the way the concept comes to signify a pattern of more densely physical orientation -i.e., by contrast to the more airy, psychic notion of sympathy frequently utilized by moral sense theorists. (Acampora, 2006, p. 76)

"Entrainment," "coherence," and "symphysis" become distinctive of a training relation that exceeds the stories we keep telling of human knowledge and the practices that accord with our speciesist pretensions to knowing all about other beings. We come to acknowledge the limits of this knowledge and, indeed, the superiority of the horse's bodily capacities beyond our own privileging of conceptual thought, rationality, discursive language, and the consequent privileging of subjectivity which essentially affords access to another's being by way of an inner movement outwards.

Training horses is undoubtedly a knowledgeable undertaking. But this knowledge is essentially of an experiential kind, being mostly the accretion of methods, techniques, tips and tricks that are tactfully applied to the specific difficulties and challenges that arise with particular horses in particular circumstances. What the stories of training show us is that many stories are possible. Some stories, however, sound better than others, particularly as training becomes a process of entrainment based on energetic exchanges and resonances. At this juncture it may be best to now put aside further discussion, reading, and writing, and turn to the practical training setting for the truths that these 
stories hold. But let us linger a while longer in the theory of horse training and, as with the "corporeal turn" referred to in the introduction, see what phenomenological insights can be gleaned from addressing more specifically the bodily configuration of the humanhorse relation.

\section{Becoming Horse}

Vicki Hearne inverts the order of knowledge in human-horse affairs. She defers to the horse's superior auditory, olfactory and kinesthetic senses, and to the horse's superior gross motor functioning:

As a consequence, human-animal relations cannot be regarded as incomplete versions of human-human relations but must be regarded as complete versions of relations between different kinds of animals....The good trainer is the one who appreciates these differences, who both understands and respects the specific nature of the animal. (Patton, 2003, p. 97)

But what sort of relation might this be, that of human and horse, when difference is duly recognized? Better still, what might this relation be when the differences in physical kind between human and horse, are not only respected but also become the basis for a different kind of being human and being horse?

Many writers regard such questions as ethical ones, leading to assertions of "animal rights." Even Hearne considers the knowledge of animals attained through working with them to be knowledge of "animal happiness," through which "many mysteries of ethics can be revealed” (Hearne, 1994, p. 232). But such ethical questions are, for Gilles Deleuze and Felix Guarratari (1987), still not correctly framed. The stories we tell ourselves about horses and the training stories into which we are drawn remain caught, if not in hard narratives of control and management, or soft narratives of care, respect and enlightened equitation, then certainly still in anthropomorphisms and projections of mimetic consciousness. Deleuze and Guattari insist that we are held linguistically, which is to say, experientially and existentially insofar as a subjectivized human being prevails, with capacities, properties and values we project onto other beings. More primary for Deleuze and Guattari than "being" this or that, and the human being to whom this or that is referenced, is "becoming," in itself. Becoming human, becoming other, becoming animal - these are the primary conditions:

Becoming is certainly not imitating, or identifying with something; neither is it regressing-progressing; neither is it corresponding, establishing corresponding relations; neither is it producing, producing a filiation or producing through filiation. Becoming is a verb with a consistency all its own; it does not reduce to, or lead back to, "appearing," "being," “equaling,” or “producing.” (Deleuze and Guattari, 2007, p. 88)

Becoming has a primacy with respect to being. Becoming animal is not then a case of 
two identifiable beings seeking a relationship, but rather a movement constantly refashioning its own object reference (Probyn, 1996, p. 59), and a movement that need not necessarily identify two separate physical beings.

Becoming animal expresses an "immanence" or "a reality that contains no negations or boundaries, but only differences and 'thresholds,' in which everything is implicated in everything else” (Urpeth, 2004, p. 103). This is, in fact, the trainer's dictum that "everything is everything else," meaning simply that which is taught in one context comes out in another. Stall behaviors appear under saddle. "Following a lead" on a longe line becomes "following a feel" in the reins. The "immanence" of becoming animal is, however, more than this simple "transfer of training." Immanence is being present to one another, becoming something other in the moment of engagement, and finding that the thing around which one is working on with horses, constitutes a becoming other at another time. The pervasive presence to one another involved in training a particular action creates a becoming animal elsewhere. There is, from the human being's perspective, the transcendence of that particular moment in the transferability of a "training effect." From the perspective of "becoming animal," however, there need be no transcendence but simply a spreading, contagious, rhizomatic immanence.

Trainers of wild animals know the reality of an "immanence" of "differences" and "thresholds" even more than those who work with domestic species. Working with wolves, Komodo Dragons, apes or wild mustangs, there is the sense of entering a space of wildness, untameability, of reaching the threshold of human consciousness. Zoos and circuses and corrals bring familiarity to bear upon the interactions, yet trainers always know that the wildness of what could easily be otherwise persists. Training is sustained and transfers to very limited effect, with trainers of wild animals ignoring the immanence of being with these animals at risk of losing their own lives. Similarly with domestic horses, we take some risk ignoring the possibility of the "demonic animal" (Urpeth, 2004, p. 90), the crazy horse, or even the friendly Arabian gelding who bolts suddenly for no immediately obvious reason. Deleuze and Guattari distinguish "three kinds of animals." First there are pets, or individuated, sentimental animals: animals we call by name, animals that are mine or yours, and that have individual histories, vet checks. "These animals invite us to regress, draw into narcissistic contemplation." A second kind of animal has "characteristics or attributes" of a species, or mythological status, or values within patterns of consumption. Then "there are more demonic animals, pack or affect animals that form a multiplicity, a becoming, a population, a tale... Or once again, cannot any animal be treated in all three ways?” (Urpeth, 2004, p. 90-91). In this last question, it is clear that these are not actually three kinds of animals. Likewise, the personalities, dispositions, or "temperaments" of horses that are promoted in their sale and training are not really distinctions of great consequence. More fundamental is the reality of immanent difference and threshold to becoming animal, beyond the points of immediate identification.

The trope "becoming animal" refers, in the work of Deleuze and Guattari (1987), to bidirectionality. "Becoming is always double, that which becomes becomes no less than the one that becomes - block is formed, essentially mobile, never in equilibrium...” (p. 
95). Becoming horse is a particular case of this "bidirectionality" insofar as we cannot separate training of the horse from the training of the human handler. Becoming horse is suggested by "horse-play" playing with horses and playing around like horses, which is to say, when "horsing around." It is active, a present participle, the gerund "horsing," just as "[t]he wolf is not fundamentally a characteristic or a certain number of characteristics; it is wolfing. The louse is lousing, and so on" (Deleuze and Guattari, 1987, p. 89). The bodily turn becomes quite radical in this sense of becoming-animal:

If there is anything still to be posited of the body, whether the body of human or horse, it is "as a set of activities rather than a substance in its own right.” Bodies are therefore always becoming rather than simply being, because they are continually constituted and reconstituted through their interactions with others in the world. Becoming body is a transaction that takes place as I am eating, riding my bicycle, making love, laughing with my child, stroking the silky back of a cat, etc.” (Acampora, 2006, p. 60)

Becoming horse, becoming animal, all becomings are bodily comings and goings. The common denominator is movement rather than the body per se. Becoming horse for the trainer puts actions of leading, longeing, and riding in two-sided connection with the actions of following, circling, going forward, moving off the leg, collecting, and contacting. The reciprocity of such actions is the intersomatic inter-action between trainer and horse in a zone of proximity. When leading the horse, for example, do I put myself at his shoulder and have him follow with his body beside and slightly behind me? Or do I see his movements and put myself in the lead, even "making the wrong thing right" by repositioning myself ahead of him when he presses forward unexpectedly? Klaus Hempfling (2006) suggests that "leading and being led blend into a shared experience. I lead the horse, the horse leads me, and we are both led in that place and time” (p. 43). The movements forward at the walk, and even more so at the trot or a canter, which bring me completely alongside the horse, have rhythm, cadence, amplitude, and duration. They start and finish according to the kinetic and kinesthetic senses of an unfolding, enfolding movement sequence.

Training horses has an optimum duration. "Get in, get out, get it done.” Training horses has also an optimum pace. "Move with, not against, the motion." These admonitions speak to durational intensities, for not only is there a sense of becoming animal in spatial proximity, there is also the sense of presentness, presencing, momentary fullness, as a temporality of vital engagement. Becoming animal is expressed essentially, or at least sensitively and sensuously, as a time that is constituted in being with the other. Amidst the corporeal exchanges, the shifting valences of movement activation and the energetic registers of exchange, there is fundamentally a sense of being in time, in tune, in synch, with the other. Becoming animal, for the trainer or horses, is an intersomatic, intercorporeal time-telling.

Let us consider further the basis for this durational characterization of the humanhorse relation, or if not its basis, then certainly the elaborated phenomenological story of an "animate consciousness" that figures in the times of becoming animal and, indeed, the 
times of becoming vitally engaged with others of a human and more-than-human world. In the next section of this paper italicized snippets of the author's horse training experience are taken as points of departure for an analysis of the consciousness that enjoins human and horse in shared becoming. These first-person accounts provide practical illustration of what might otherwise remain too philosophical an analysis of horse training. At the same time, the limits of the preceding analysis of "becoming horse" may well become clearer in reference to a pedagogical paradigm that, in its training story, may not turn so decidedly corporeal and animal as that analysis has suggested.

\section{Animate Consciousness}

I've ridden, played with and otherwise connected with the Arabian gelding, Mojo, these past five years, but it has never been as deep a connection as I can make with Spartacus, the recently-gelded Andalusian. I've always had to "ride" Mojo and "think about" what I am doing. You could say we've never been really on the same wavelength. But with Spartacus there is just a more immediate, visceral connection. The last few days I have been playing with his gaits, energistically, and find he can suddenly do incredible motions that it takes years to develop in dressage-trained horses. I seem to be drawing out motions that he already knows how to do. Yet feeling him become energized in specific gaits and patterns, do canter pirouettes and tempi changes, almost by just letting them happen, makes me want to plug more deeply into this "connective tissue" of riding.

Merleau-Ponty's last lectures On nature were cited at the start of this paper. But it is in his first work, The structure of behaviour (Merleau-Ponty, 1963), that one finds clues to the later thinking and, particularly, the analysis of the dialectic of the physical, vital and human orders of behaviour that prefigures the later "animal turn." It is not necessary to rehearse Merleau-Ponty's earlier or indeed later analyses here, except to take from the earlier work the idea of "vital structures" of consciousness that catch physical determinants of animate being within "nuclei of signification, certain animal essences" (p. 159). But whereas Merleau-Ponty was quick to press this order of signification in service of human consciousness, it may be more telling to remain with "animal essences" and the vital, animate consciousness that is disclosed. This is no reversion to "vitalism or animism" (p. 161) but recognition of behaviours that, in the nexus of human and animal, are not the property of a strictly "human order" of significance. They are behaviours of becoming animal that appear in the human-horse connection described above as surprising, delighting movements. They are movements that, cued initially from the side of human intention, are offered by the horse as if second-guessing human intentionality.

Maxine Sheets-Johnstone, (1999) provides us with the notion of "animate consciousness" to account for such experiences of the nature of being with horses as their movements become more than one can ask, literally and gesturally, of them. For SheetsJohnstone, the "primacy of movement" registers with, and resonates in, our "kinesthetic and kinetic experiences" prior to any reflective awareness of "self-movement" (p. xviii) and the movement of others. We participate in a world of constantly changing animations, alive with others in lively exchanges that are characterized essentially by felt 
tensional qualities and energetic registrations.

Spartacus and I are practicing some tricks with carrot rewards when he offers me something for which I have not asked. I take it, and then plug into that particular motion in terms of its vitality affects. It is a backwards walk to me, which I have been working on by holding his tail and tapping his croup. But then he just starts backing up as I walk behind him. That is the goal to which I am heading, but I do not expect just to be given it so readily. The challenge then becomes one of picking up this motion and developing it further. So I think, what if Spartacus is the "horse" trainer and I am the human performer, what can he teach me to do? He then teaches me to back up even more quickly, which next shows me how to stay beside him while he runs through his various gaits. "Smart boy, for doing that," which is just another way of misinterpreting him. There need be no human story of superior intellect or some such collapse of the intensities and flows of creative duration.

The horse's movements become animated in the degree to which human intention yields to a kinesthetic awareness of, and responsiveness, to, the "vitality affects" and revitalizing possibilities of further affecting those movements (cf. Sheets-Johnstone, 1999, pp. 156-162; 256, 257). "Vitality affects" are characterized as the energy activations to the movements performed such that one can discern movements that are bursting, rushing, surging, flowing, ebbing, and fading. "Bringing up life in the horse" or "breathing into the spaces of riding" are but two expressions from the world of horse training that speak to the matching and intentional kinesthetic modulation of the vital affects that are sensed in the horse's motions. "Our kinetic inter-attunement is grounded in a natural sensitivity to the movement of others, and in a correlative natural sensitivity to kinetic meaning” writes Sheets-Johnstone (p. 229).

Sheets-Johnstone asserts "an original kinetic liveliness or animation" into which we are born (p. 232), a "primal animation" (p. 247), "sheer movement...as the ground on which intentionalities initially develop" (p. 252)." She locates this animation in ontogenetic development that partakes of "the sheer kinetic spontaneity with which a vast and incredible diversity of animate forms comes into the world" (p. 271); yet human animation seems still to remain somewhat apart from this "vast and incredible diversity." Returning, then, to the notion of "becoming animal," now tied to an "original kinetic liveliness or animation, the words of Deleuze and Guattari take on added meaning:

We can know nothing about a body until we know what it can do, in other words, what its affects are, how they can or cannot enter into composition with other affects, with the affects of another body, either to destroy that body or to be destroyed by it, either to exchange actions and passions with it or to join with it in composing a more powerful body.” (Deleuze and Guattari, 1987, p. 92)

If "vitality affects" are the characteristics of animate consciousness, then "the reality of becoming animal is affect in itself" (p. 93). Human animation, in its affectations, breaks into becoming animal by arresting "the circulation of affects" (p. 93). At its extreme in 
horse training, such affectation is the posturing or horse breaking. But it is also, to some extent, horse riding, horse leading, or any other training action that arrests "the circulation of affects.”

I run beside Spartacus. We have been working for some time on leading, first having him stay at my shoulder, and then stopping on cue without crowding. He tends to fall into me as he stops, with the correction requiring that I hold the lead shank well away from me. We've worked on having him move away with pressure on his neck and turning to the outside through pressure on the lead rope and clear signals to the outside. Now, walking beside him, I signal similarly, but I feel his tendency to crowd me, especially when I prompt a canter and he circles inwardly, always risking stepping on me. Then, at the trot, I sense a cadence I can match. We run side by side, holding the space in-between. I increase my tempo, holding that cadence, and turn into this in-between space, but instead of it collapsing, Spartacus holds his distance by stepping to the outside. We straighten, and then cueing the canter with a hippity-hop, Spartacus and I continue with matched intensity, same cadence, holding the same space between us.

There is a breakthrough in the human-horse relation. What seemed for so long disobedience on the horse's part, or at least not knowing the boundaries for ensuring human safety, now presents as a vibrant connection of movement possibilities. Corrections give way to mutual participations in movement. But do we "cross a threshold, to reach a continuum of intensities that are valuable only in themselves, to find a world of pure intensities where all forms come undone, as do all the significations, signifiers, and signifieds, to the benefit of an unformed matter of deterritorialized flux, of nonsignifying signs” (p. 96)? There are still defined positions, asked-for movements, gait changes that are cued, still an operative intentionality in play. Can there ever be in the horse training relation "a becoming that includes the maximum of difference as a difference of intensity, the crossing of a barrier, a rising or a falling, a bending or an erecting, an accent on the word” (p. 99)?

The question supposes a difference that is impossible to surmount. But this is a difference that is more deferral, a playful back and forth movement of intensities. Again, we need not posit another being with whom we must learn to become other than ourselves. Instead, it may be possible to recognize in the inter-action, in the human-horse connection, the bodily affordances we have to become animal. Alphonso Lingis (2003) writes of the "inhuman movements and intensities in us" that already put us indelibly in the animal world:

Our bodies are coral reefs teeming with polyps, sponges, gorgonians, and free-swimming macrophages continually stirred by monsoon climates of moist air, blood, and biles. Movements do not get launched by an agent against masses of inertia; we move in an environment of air currents, rustling trees, and animate bodies. Our movements are stirred by the coursing of the blood, the pulse of the wind, the ready rhythms of the cicadas in the autumn trees, the whir of passing cars, the bounding of squirrels and the tense, poised pause of deer. The differentials of speed and 
slowness liberated from our bodies do not block or hold those movements only; our movements compose their differential, directions, and speeds with those movements in the environment. Our legs plod with elephantine torpor; decked out fashionably, we catwalk; our hands swing with penguin vivacity; our fingers drum with nuthatch insistence; our eyes glide with the wind rustling the flowering prairie. (p. 167)

Our movements, as "they surge and ebb in intensity "(p. 167), pick up the intensities of other beings.

I've been preparing Spartacus for liberty riding, which means forsaking the use of bridle and saddle. He has learned to stand still while being mounted under saddle and to take body weight across his back without the saddle support. Now, with still the use of a lead rope serving as a rein, he is put by the mounting block and complies as he has been trained to do to allow me to lift my leg over his back and sit astride him. We move off, but there is steering only to the side on which the lead rope lies. He turns in this direction and resists turning otherwise, even with the urgings of my legs and seat. I force the issue with my legs, giving a sharp heel reminder to move off the pressure. We are in tension, his body stiffening with mine seemingly for an impending battle that I will surely lose. Yet, in the moment, another possibility affords itself. I feel a softening in his neck as I loosen the lead rope. A further softening occurs as I exchange the rope's tautness for a softer urging to turn the other way. This rope holds capacities for extension as well as flexion, for bending from as well as to it. The rope becomes a chord of attenuated connection as I feel action and response flow from one end to the other, and from both ends at once. What possibilities of liberty riding are now available without the rope?

The rope, as leverage, gives way to more subtle tensional qualities. The unidirectional strength of pulling is now, at times, drawing, extending, placing, fluttering, even caressing the horse's neck. But does this differentiated connection go as far as Lingis suggests in connecting to the energies of elemental otherness?

The woman who rides a horse lurches with the surges of its impulses, while the horse trots with her prudent programming. The movements of her body are extending differential degrees of speed and retardation, and feeling the thrill of speed and the smoothing decompression of retardation. These movements are not productive, they extend neither toward a result nor a development. They are figures of the repetition compulsion; one strokes a calf each night on a farm, one rides a horse through the woods with the utterly noncumulative recurrence of organism. (p. 169)

Lingis suggests a connection, a becoming animal, that is beyond the training relation with its eye still on an intended action. Perhaps he suggests an impossible connection, only imaginable in another kind of story, beyond training stories, of becoming animated with other beings. What can be gleaned from Lingis's sense of human-horse connection, however, is the temporality of such intense interaction. Movements with another, in the registration of their vitality affects, their intensities, are "spreading's of duration" (p. 
168). Such duration may have a beginning, a movement prompt, a cue, a riding aid, but durational intensity is "a line of becoming" with seemingly "neither beginning nor end, departure nor arrival, origin nor destination” (Deleuze and Guattari, 1987, p. 94). The duration of intense connection, for both Lingis's rider and for the goal-oriented horse trainer, is contingent on being "in the middle," "in-between" different loci of action, right in the midst of movement (p. 94).

Training Spartacus has become a kind of play. What we do from day to day is determined by the coming together of our interests, enthusiasms, and the environmental affordances of the weather, the space available, even the time of day. We enter this play within the movements that one of us prompts, but this is more of an opening, an invitation, to the movements that are possible at this time, in this moment, and for a certain undetermined duration. Sometimes the movements of high school dressage are possible where, say, a side-ways canter is offered out of the discipline of practicing a shoulder-in. Other times there are the tricks of Spanish walk, bowing, levading that are offered with little urging. And sometimes, on a spirited ride home, the call and scent of other horses gives rise to piaffe and passage. These motions are trained in the moments of their arising. The skill, the real trick of training, is learning to be open to these moments and being in the middle of them in order to extend their durations.

There is "the cardinal structure of time" that is experienced "physiognomically in the rhythms of breathing, exhaling and inhaling into the relaxation and looseness needed for establishing the horse's working gaits (cf. Sheets-Johnstone, 1999, pp. 156-162). This temporality, as a feel for movement, is also experienced in accelerating, crescendoing rhythms of breathing, in elevated balancing, and staccato touches, that cue and match the more extended and elevated gaits. The ordinality of time, its beginnings, proceedings and endings, tends to obscure "the cardinal structure of time" as qualitatively, essentially kinetically and kinesthetically, experienced. "Time," writes Sheets-Johnstone, "is not fundamentally akin to the notes of a melody, one note strung out after the other in ordinal before-now-after fashion, but is an unfolding qualitative dynamic" (p. xxii). Time is essentially duration intensity. We become in time with others, in tune with them, for a fleeting moment, in a burst of enthusiasm, a rush of excitement. Yet there are longer durations, also, of rising waves and extended flows, which make us lose track of ordinal time. These durations of engagement with others of the human and more-than-human world begin to form a habit and style of being animatedly conscious, not hurried or harried in the press of things to get accomplished, but being kinetically, kinesthetically, aesthetically and energetically available to the interplay of movement in-between humans and horses.

\section{Conclusion}

Many stories of training horses are premised on hierarchical relations, imitative of those relations of dominance and submission that appear in horse herds, and consistent with the hierarchies of human cohabitations. Yet, paradoxically, such relations need not be sustained in the actual work of training horses. Certainly there is no great symmetry between human and horse, even though postural, positional, gestural and expressional 
alignments can be made. But this fact need not require us to suppose human capacities of consciousness that subordinate the consciousness of horses. Instead, we can view the human-horse relation as a "lateral union" (Smyth, 2007) and a kinship of beings that encounter one another side-by-side rather than face-to-face. From training to entrainment, the human-horse relationship is a drawing out of the horse's latent movement possibilities, while drawing near and, at times, seemingly together, to explore the horse's capacity for becoming animated, enlivened, in the "perfection" of its movements, all the while becoming intensely enfolded, within the flesh of an unfolding interaction. There is surely, if we are open to it, "the play of an inside that opens onto an outside, an outside that expresses itself within" (Toadvine, 2009, p. 135). Yes, still it is with the human purposes of "training" another animate being that this relation between human and horse can become something other than a hierarchical imposition. There can come the recognition that "non-human animals are 'variants' of the same sensible-sensing corporeality as humans" and that "what exists are not separate animals, but an interanimality” (Merleau-Ponty, 2003).

With interanimality, it is a matter of resignifying the 'naturalness' of the natural attitude in a way that restructures the perception of our belongingness to nature by generating, among others, the phenomena of human-animal 'kinship.' Contrary to the theoretical proclivities of constructive phenomenology, the crucial point is that there is no pre-existing ontological truth behind this kinship. Rather, what is at issue is nothing more nor less than its realization. (Smyth, 2007, p. 200)

Such realization of interanimality is caught in the play of "immanence" and "transcendence" that has been mentioned through this paper. It was spoken of initially in terms of the "linguistic turn" that tends to overplay the transcendence of human consciousness, with overemphasis on human capacities for language, rational thought, and the construction of stories of human superiority. This "linguistic turn" always risks confining us to a "transcendent" human consciousness from which there can be no "other" escape. The "corporeal turn," however, brings us to the "immanence" of being with others and the possibilities of vital, animate consciousness. This "corporeal turn" nevertheless risks reducing animation to realms of "self-movement," purposive movement, which is to say, human movement, and casting animate consciousness within "physical, vital and human" orders of existence. The "animal turn" is a newer linguistic turn in philosophy and the social sciences that turns corporeally also to other beings, with the intention of showing transcendence and immanence to actually be of the same nature, if not order, of things.

Training horses provides an explication as well as a test of how far we might turn to the animal. In this practice, it remains uncertain to what extent the stories we tell of nondominant approaches can take us beyond ourselves to engage in actions that are reflective of the good story being told of "becoming animal." But what seems compelling is that something of this becoming can be achieved when connecting with horses in more lateral unions and kinships of animated responsiveness. We find glimpses of such becomings in moments of surprising connectivity. Accordingly, the trainer's challenge, if not the philosopher's, is to have such moments endure, sustaining a feeling, a connection, a 
relation, for the sake becoming other, growing, and forming oneself as increasingly adept and responsive to other beings. Vitality, vital engagement with other beings, and the revitalization of our lives as humans on this interconnected planet is ultimately what is at stake in this project of becoming horse in the duration of the moment.

\section{References}

Abram, D. (1997). The spell of the sensuous: Perception and language in a more-thanhuman-world. New York: Vintage.

Abram, D. (2010). Becoming animal: An earthly cosmology. New York: Pantheon Books.

Acampora, R.A. (2006). Corporal compassion: Animal ethics and philosophy of the body. Pittsburgh: University of Pittsburgh Press.

Atterton, P. \& Calarco, M. (Eds.) (2004). Animal philosophy: Ethics and identity. New York: Continuum.

Bekoff, M. (2007). The emotional lives of animals. Novato, CA: New World Library.

Bekoff, M. (2010). The animal manifesto: Six reasons for expanding our compassion footprint. Novato, CA: New World Library.

Calarco, M. (2008). Zoographies: The question of the animal from Heidegger to Derrida. New York: Columbia University Press.

Carpenter, B. (2006). Energetic training, parts 1 and 2. Retrieved August 30, 2010 from http://www.hashknifehorses.com/energetic_training_part_1.htm; http://www.hashknifehorses.com/energetic_training_part_2.htm

Deleuze, G. \& Guattari, F. (1987). A thousand plateaus. In M.Cararco \& P. Atterton (Eds.) (2004), Animal philosophy: Essential readings in continental thought (pp. 87-100). London: Continuum.

Derrida, J. (2008). The animal that therefore I am (D. Wills, Trans.), New York; Fordham University Press.

Dufresne, P. (2011). Training for Courage: Endotapping parts 1-4. Retrieved February 13, 2011 from http://www.pkequestrian.com/articles.html

Evans, N. (1995). The horse whisperer. New York: Delacorte.

Foley, S. (2007). Getting to yes: Clicker training for improved horsemanship. Neptune City, NJ: T.F.H. Publications.

Fudge, E. (2008). Pets. Stocksfield, UK: Acumen.

Giacomini, J.P. (2010). Equus Academy: EndoTapping Video Library. Retrieved January 10, 2011 from

https://www.equus-academy.com/ea_public/eapub_content/VidQueryEndoTapping.php 
Grandin, T. and Johnson, C. (2009). Animals make us human: Creating the best life for animals. Orlando, FL: Houghton-Mifflin Harcourt.

Harraway, D. (2008). When species meet. Minneapolis: University of Minnesota Press.

Hearne, V. (1994). Animal happiness: A moving exploration of animals and their emotions. New York: Skyhorse.

Hearne, V. (2007). Adams’s task: Calling animals by name. New York: Skyhorse.

Hempfling, K.F. (2001). Dancing with horses: Collected riding on a loose rein. K. McCormack (Trans.). North Pomfret, Vermont: Trafalgar Square.

Hempfling, K.F. (2004). What horses reveal: From first meeting to friend for life. North Pomfret, Vermont: Trafalgar Square.

Karrasch, S, Karrasch, V. and Newman, A.J. (2000). You can train your horse to do anything: On target training: Clicker training and beyond. Addington, UK: Kenilworth.

Kurland, A. (2007). Clicker training for your horse. Waltham, MA: Sunshine Books.

Lingis, A. (2003). Animal body, inhuman face. In C. Wolfe (Ed.), Zoontologies: The question of the animal (pp. 165-182). Minneapolis, MN: University of Minnesota Press.

May, M. (2008). The path of the horse. Documentary, Stormy May Productions, www.stormymay.com

Melson, G. F. (2001). Why the wild things are: Animals in the lives of children. Cambridge, MA: Harvard University Press.

Merleau-Ponty, M. (1963). The structure of behavior. A.L. Fisher (Trans.), New York: Beacon Press.

Merleau-Ponty, M. (2003). Nature: Course notes from the Collége de France. R. Vallier (Trans.), Evanston, Ill: Northwestern University Press.

Miller, R.M. \& Lamb, R. (2005). The revolution in horsemanship: And what it means to mankind. Guilford, CT: Lyons Press.

Morgan, M.H. (1962). The art of horsemanship by Xenophon. London: J.A. Allen.

Nevzorov, A. (2006). The horse crucified and risen. Retrieved July 1, 2010 from http://www.hauteecole.ru/en/horse_encyclopaedia.php?sid=0\&id=967

Patton, P. (2003). Language, power, and the training of horses. In C. Wolfe (Ed.), Zoontologies: The question of the animal (pp. 83-99). Minneapolis, MN: University of Minnesota Press. 
Pignon, F., Delgado, M., \& Walser, D. (2009). Gallop to freedom: Training horses with the founding stars of Cavalia. North Pomfret, Vermont: Trafalgar Press.

Probyn, E. (1996). Becoming horse in Outside belongings. New York: Routledge.

Sheets-Johnstone, M. (1999). The primacy of movement. Amsterdam: John Benjamins.

Sheets-Johnstone, M. (2009). The corporeal turn: An interdisciplinary reader. Exeter, UK: Imprint Academic.

Smyth, B. (2007). Merleau-Ponty and the generation of animals. PhaenEX: Journal of Existential and Phenomenological Theory and Culture,2 (2), 170-205.

Toadvine, T. (2009). Merleau-Ponty's philosophy of nature. Evanston, Ill: Northwestern University Press.

Urpeth, J. (2004). Animal becomings. In M.Cararco \& P. Atterton (Eds.) (2004), Animal philosophy: Essential readings in continental thought (pp. 101-110). London: Continuum.

* My involvement with horses comes from a lifetime of riding other people's horses. These were mostly farm horses, which is to say, they were coarse, unschooled, clumsy-gaited horses who had the good fortune of a paddock-grazing life, with just some cattle mustering to be done every now and then. The 'trainer's challenge' arose some years ago with the ownership of my own horses, 'performance horses,' which is to say, with the acquisition of expensive, well-bred horses to which are attached high expectations of equine gymnastic development and horse riding competence. The present paper reflects the growth in my understanding of what it means to be in partnership with rather than simply being on top of horses. The sections on 'training horses' and 'becoming horse' are silently referenced to this personal story of seeking connection with horses. It is a personal story that comes into the open in the third section of the paper, on 'animate consciousness,' through specific reference to how I play with my horses. 